\title{
CASE STUDY IN SYSTEMATIC DESIGN ENGINEERING - STAGE BARGE GANGWAY
}

\author{
W. Ernst Eder \\ Royal Military College of Canada (retired) \\ eder-e@kos.net
}

\begin{abstract}
Students learning design engineering at times need a good example of procedure for novel design engineering. The systematic heuristic-strategic use of a theory to guide the design process - Engineering Design Science - and the methodical design process followed in this case study is only necessary in limited situations. The full procedure should be learned, such that the student can select appropriate parts for other applications.

This case example is presented to show application of the recommended method, and the expected scope of the output, with emphasis on the stages of conceptualizing. The case follows a novel design problem of a gangway for ship-shore transfer for the Caravan Stage Barge.
\end{abstract}

Keywords: Systematic engineering design, conceptualizing, application of methods

\section{INTRODUCTION}

Students learning design engineering at times need a good example of procedure for novel design engineering. The systematic and methodical design process followed in this case study is abridged from [1],[2],[3],[4]. As shown in papers presented at a previous conference [5],[6], such a fully systematic procedure is only necessary in limited situations, when an engineering designer is faced with an unfamiliar and non-routine situation.

Creativity [7] is usually characterized by a wide search for solutions, especially those that are innovative. This search can be supported by the recommended systematic and methodical approach. All generated alternatives should be kept on record, to allow re-tracing and recovery from subsequent detection of a better alternative. Each step in the overall procedure should be concluded by selecting the most appropriate (one or two) solutions for further processing, in order to control a tendency towards 'combinatorial complexity'.

The primary purpose of these case studies is to present examples for procedural application of the recommended engineering design method that students and practitioners can follow and study to help learn the scope of the method and its models. This purpose has been applied in courses at the Eidgenössische Technische Hochschule (ETH) by Dr. Vladimir Hubka (1976-2000), at The Royal Military College of Canada (1981-2006) by the author, and at the University of West Bohemia (1990-present) by Prof. Stanislav Hosnedl - for all levels of education and for industry consultations. A secondary purpose was to verify and validate the theory and its models, and the method derived from the theory. The emphasis in all case studies was on the engineering design procedure and use of the models.

The systematic procedure must be adapted to the problem. The cases demonstrate that an engineering designer can idiosyncratically interpret the models to suit the problem, and develop information in consultation with a sponsor. Opinions will vary about whether a requirement should be stated in the class of properties as shown, or would be appropriate in a different class.

This case example is presented to show application of the recommended method, and the expected scope of the output, with emphasis on the stages of conceptualizing. The embodying/laying out and detailing stage is regarded as more routine.

The author's purpose is "to clarify (by duly complicating) important issues" [8] about engineering designing as a process, to show that systematic methods and intuitive procedures (creativity) work very effectively together.

This is the latest (number 22) in the series of case examples, reaching from 1974 to the present. Since 2010 [4], these case examples have been presented at the current latest stand of development of both the theory of technical systems, and the recommended systematic design process

Progress of design engineering is shown, starting from defining the requirements, using sketches and the thoughts and discussions (with Stage Barge personnel) that accompanied them. Relationships of these thoughts and discussions to existing design theory are shown, especially during conceptualizing.

The design process was necessarily iterative, but showed many signs of systematic procedure, and 
recursive, the problem had to be broken down into smaller but interacting sections.

This report is a post-hoc reconstruction from the author's records. It is subjective, anecdotal, and cannot be verified. No attempt was made to create a formal research protocol. The process took place over a period of about four weeks, at the Stage Barge, in the author's office at $\mathrm{RMC}$, and even at home.

PROCEDURAL NOTE: Compare the output of each stage with the theoretical figures from [3], [4] to check whether any important elements may be missing. Such procedural notes are interspersed with the case to explain some aspects of the procedure.

\section{CASE STUDY - STAGE BARGE GANGWAY}

Founded in 1970, the Caravan Stage Company [9] travelled in Canada and the U.S.A. from place to place, and performed self-scripted plays. Around 1992 they decided to have a steel replica of a wooden River Thames (London, England) sailing barge designed and fabricated in a small dockyard in Kingston, Ontario, Canada. The Thames sailing barges carried bulk goods such as coal. The stage barge took four years to complete, $30 \mathrm{~m}$ length, $7.2 \mathrm{~m}$ beam, $1.3 \mathrm{~m}$ draft, single mast, fore-and-aft rigged sails, $316 \mathrm{~m}^{2}$ sail area, about 90 tonne displacement. All materials and OEM parts were donated to the Caravan Stage Company. The superstructure was the stage for performances, with the audience on shore. The stage barge was to be fully independent, with its own power supply (two diesel motors), lighting and sound amplification system, galley and sleeping accommodation, etc.

For purposes of access from shore to ship, especially for the actors during a performance, an easily fitted and removed gangway system is needed.

The author was initially contacted in 1994 by Paul Kirby, producer of the Caravan Stage Company, via the Head of Mechanical Engineering, The Royal Military College of Canada (RMC) to help by designing various items, e.g. (in 1996) this gangway system.

Steps from the procedural model [3],[4 (figure 11.1, $\mathrm{p}$. 219-222)] were considered, and the following review cycle was applied for each step:

$\{$ Improve, optimize $\}-<$ Substantiate, evaluate, select, decide $>-\{$ Verify, check, reflect $\}$

\section{- task defining:}

(P1) establish a design specification for the required system, a list of requirements;

Requirements are listed only under the most relevant TrfP and/or TS-requirements class as judged by the engineering designer, and cross-referenced if they are repeated in any other relevant requirement class [4 (figure 11.4 , p. 226-227)]. Indication of priority $-\mathrm{F}$... fixed requirement, must be fulfilled; S ... strong wish; W ... wish; N ... not considered.

Rq1 OrgRq Organization requirements $(\mathrm{Rq} 1 \mathrm{~A}-\mathrm{Rq} 1 \mathrm{E})$

$\mathrm{F}$ Design and manufacture by RMC, Dept of Mechanical Engineering.

Rq2 TrfRq Requirements of the Transformation (Rq2A

$$
-\mathrm{Rq} 2 \mathrm{E})
$$

F Actors and visitors must easily and safely be able to move from the barge to the shore during a performance, and at other times, walking or running,

F Three persons per meter (one person per foot) should be accommodated,

F $0.7 m(28 ")$ wide,

F Two lengths. $3 m(10 \mathrm{f}) \mathrm{t}$, and $6 m(20 \mathrm{ft})$ reach from barge to land readily available from the unit,

F Maximum length for storage should be no more than $3 m(10 \mathrm{ft})$,

$\mathrm{S}$ minimum weight and thickness desirable, it should be handled by two persons, a gantry rig is available for hoisting if needed.

Rq3 EfRq Effects requirements of the TS (Rq3A $\mathrm{Rq} 3 \mathrm{C})$

F Protective safety ropes must be attached to avoid people falling off sideways (added in TrfP - P3a),

F From its storage location on deck, the gangway must be either assembled on deck and then lifted out, or sections lifted out onto shore and assembled there (added in $\operatorname{TrfP}-\mathrm{P} 3 \mathrm{a})$,

F Vertical load forces to be reacted to local ground (shore and barge) at both ends, horizontal forces to be reacted to the barge, and through the mooring ropes to the shore,

F Barge end to be fitted to the railing such that it can rotate through small angles, say $10^{\circ}$ horizontal, $30^{\circ}$ vertical (added in TrfP P3a).

F All turnbuckles, cables, other fasteners, etc., to remain permanently attached to constituent parts of the gangway (added in Preliminary Layout - P5a).

Rq4 MfgRq Manufacturing requirements

F All fabrication in house at RMC Mech. Eng. Dept., or on site at Stage Barge.

Rq5 DiRq Distribution requirements None - delivery from RMC to the Stage Barge.

Rq6 LiqRq Liquidation requirements

F Non-toxic materials. 
Rq7 HuFRq Human factors requirements (Rq7A -

$$
\text { Rq7G) }
$$

No sharp edges, min. danger of catching or tripping - non-slip covering of tread surface.

Rq8 TSFRq Requirements of factors of other TS (in their TrfP) (Rq8A - Rq8G)

Rq9 EnvFRq Environment factors requirements, LC1 -

$$
\text { LC7 (Rq9A - Rq9B) }
$$

F Avoidance of corrosion / rusting.

Rq10 ISFRq Information system factors requirements,

$$
\text { LC1 - LC7 (Rq10A - Rq10F) }
$$

Rq11 MgtFRq Management factors requirements

Rq11A Management planning, LC1

Rq11B Management of design and manufacturing process, LC2 - LC4

Rq11C Design documentation, LC2

F Original drawings to remain at RMC, copies held by Stage Barge.

Rq11D Situation, LC2

Rq11E Quality system.

Rq11F Information requirements

Rq11G Economic requirements

Rq11H Time requirements

Rq11J Tangible resources

Rq11K Organization

Rq11L Supply chain requirements

F Obtain donated items before start of detail design.

Rq11M Other management aspects

DesRq Engineering design requirements for $\operatorname{TrfP}(\mathrm{s})$ and None.

$$
\mathrm{TS}(\mathrm{s})(\mathrm{Rq} 12-\mathrm{Rq} 14)
$$

(P2) establish a plan and timeline for design engineering;

Detail design to be completed before end July 1996.

- conceptualizing:

(P3a) from the desirable and required output (operand in state Od2), establish a suitable transformation process $\operatorname{TrfP}(\mathbf{s})$;

(P3.1.1) if needed, establish the appropriate input (operand in state Od1);

(P3.1.2) decide which operations in the $\operatorname{TrfP}(\mathrm{s})$ will be performed by technical systems, TS, alone or in mutual cooperation with other operators; and which TS(s) (or parts of them) need to be designed;

Discussions with the Stage Barge personnel, using sketches and developing thoughts to accompany these sketches resulted initially in the transformation process, see figure 1, which also added some items to the design specification.

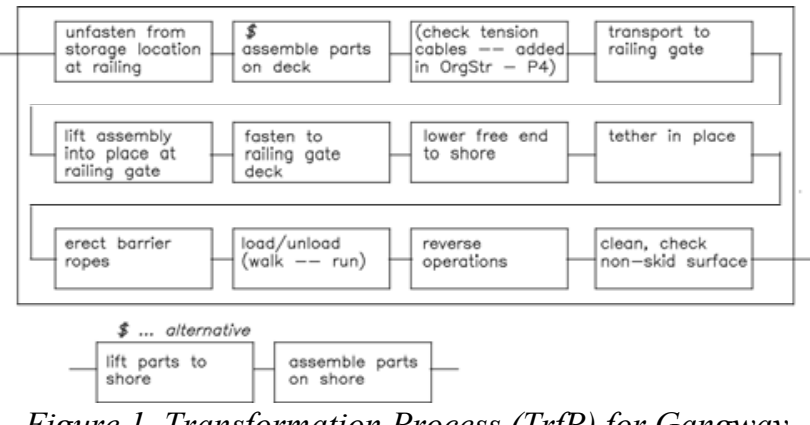

Figure 1 Transformation Process (TrfP) for Gangway

(P3.1.3) establish a technology (structure, with alternatives) for that transformation operation, and therefore the effects (as outputs) needed from the technical system;

A moving people-load causes a bending stress of the gangway. The thickness of a four-in-parallel extruded channel section in aluminum would need to be about 200 $\mathrm{mm}$ (8"), compared to $100 \mathrm{~mm}$ (4") maximum as desirable. If the length of each bending section can be reduced to $1 \mathrm{~m}(3 \mathrm{ft})$, the thickness need only be $100 \mathrm{~mm}$ (4"), e.g. by a steel pre-tensioning cable round supports below the gangway deck. The supports needed to be 75 $m m$ (3") high, the cable could thus be permanently installed inside the thickness of the gangway for each $3 \mathrm{~m}$ (10 ft) length, pre-tensioned by turn-buckles.

The stanchions (uprights) to hold the safety barrier ropes could be hinged to the gangway, or plugged in. The shore end of the gangway can either slide or roll on castors on the shore surface.

A sample of exploratory 'what if' investigations is shown in figure 2 .
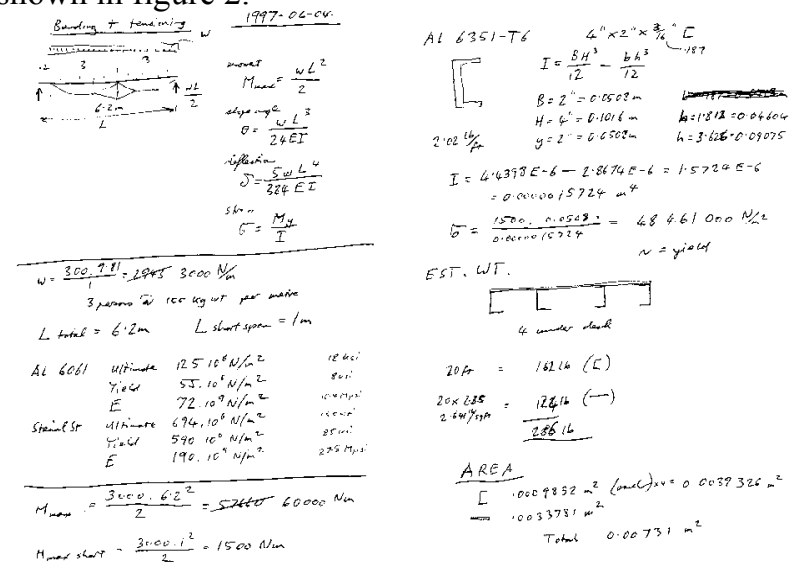

Figure 2 Technologies - Exploratory Investigation for Gangway

(P3b) establish what the technical system needs to be able to do (its internal and cross-boundary functions, with alternatives); 
Short end sections were also needed at the barge and at the shore, with hinged ramp pieces, to avoid presenting severe tripping hazards from steps.

The TS-function structure developed for this project is shown in figure 3. The TS-function 'present good appearance' is a special feature of this problem, it could be solved with the help of an industrial-artistic designer. Only the numbered functions are variable, and therefore entered into a morphological matrix.

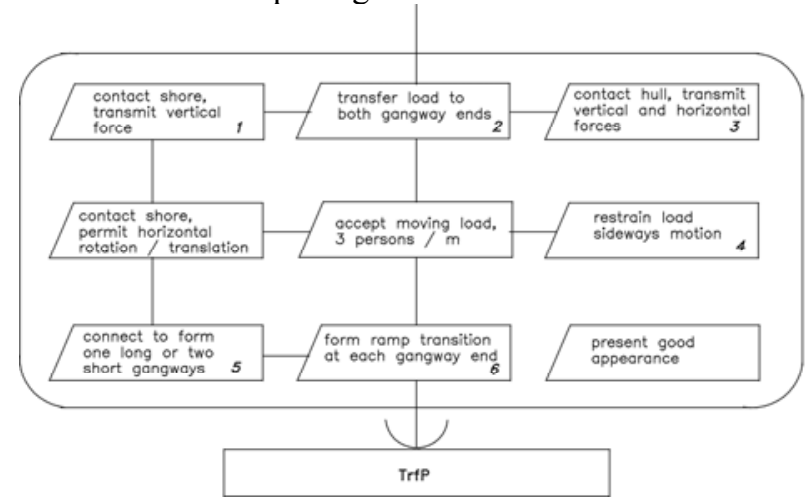

Figure 3 TS-Function Structure for Gangway

\section{(P4) establish what organs (function-carriers in principle and their structure, with alternatives) can perform these functions;}

All joints between the lengths needed to be pulled tight, e.g. by turn-buckles, see figure 4 , the selected size was $3 / 8 \times 6$. Similar pre-tensioning can be used at the joint between the two lengths. To ensure that this pre-tension cable is always attached, a short mid-section was included to carry this cable. The ends of each length and the midsection had to be different, to exclude wrong assembly.

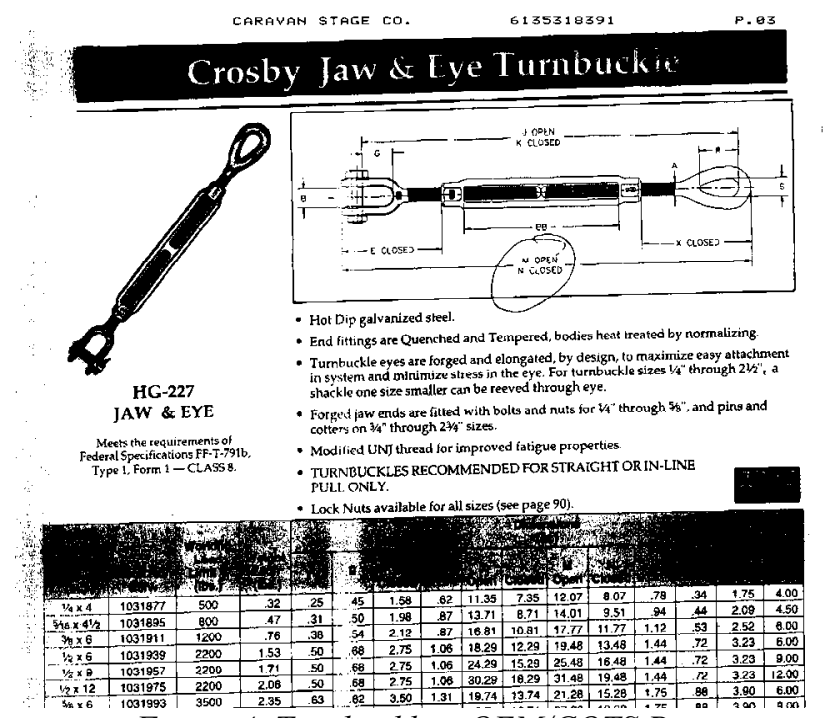

Figure 4 Turnbuckle-OEM/COTS Part

Plugging of the safety barrier stanchions was chosen to maintain the $100 \mathrm{~mm}$ (4") thickness without protrusions. Each upright has two short horizontal tubes to allow threading two ropes at suitable heights, which seems to be acceptable for marine use.

Figure 5 shows a morphological matrix, and figure 6 shows the selected TS-organ structure.

\begin{tabular}{|c|c|c|c|}
\hline & TS-function & \multicolumn{2}{|c|}{ Partial Solution Proposal } \\
\hline 1 & $\begin{array}{l}\text { contoct shore, } \\
\text { transmit vertical } \\
\text { force }\end{array}$ & sliding pods & caster wheels \\
\hline 2 & $\begin{array}{l}\text { transfer load to } \\
\text { both gangway ends }\end{array}$ & beam bending & $\begin{array}{l}\text { beam bending with } \\
\text { cable tension support }\end{array}$ \\
\hline \multirow{2}{*}{3} & \multirow{2}{*}{$\begin{array}{l}\text { contact hull, transmit } \\
\text { vertical and horizontal } \\
\text { forces }\end{array}$} & sliding pads & caster wheels \\
\hline & & \multicolumn{2}{|c|}{ tether attachment to Stage Barge hull } \\
\hline 4 & $\begin{array}{l}\text { restrain load } \\
\text { sideways motion }\end{array}$ & $\begin{array}{l}\text { ropes held in } \\
\text { plugged stanchions }\end{array}$ & $\begin{array}{l}\text { ropes held in } \\
\text { hinged stanchions }\end{array}$ \\
\hline 5 & $\begin{array}{l}\text { connect to form } \\
\text { one long or two } \\
\text { short gangwoys }\end{array}$ & $\begin{array}{l}\text { end-to-end connection } \\
\text { between sections }\end{array}$ & \\
\hline 6 & $\begin{array}{l}\text { form ramp transition } \\
\text { at each gangway end }\end{array}$ & fixed ramp & hinged ramp \\
\hline
\end{tabular}

Figure 5 Morphological Matrix for Gangway

PROCEDURAL NOTE: Figures 6 and 7 demonstrate that students should learn sketching by hand as a representation tool. Figures 1, 2 and 3 would normally be drafted as hand-sketches, and only for a permanent record re-'drawn' using a computer, as shown.

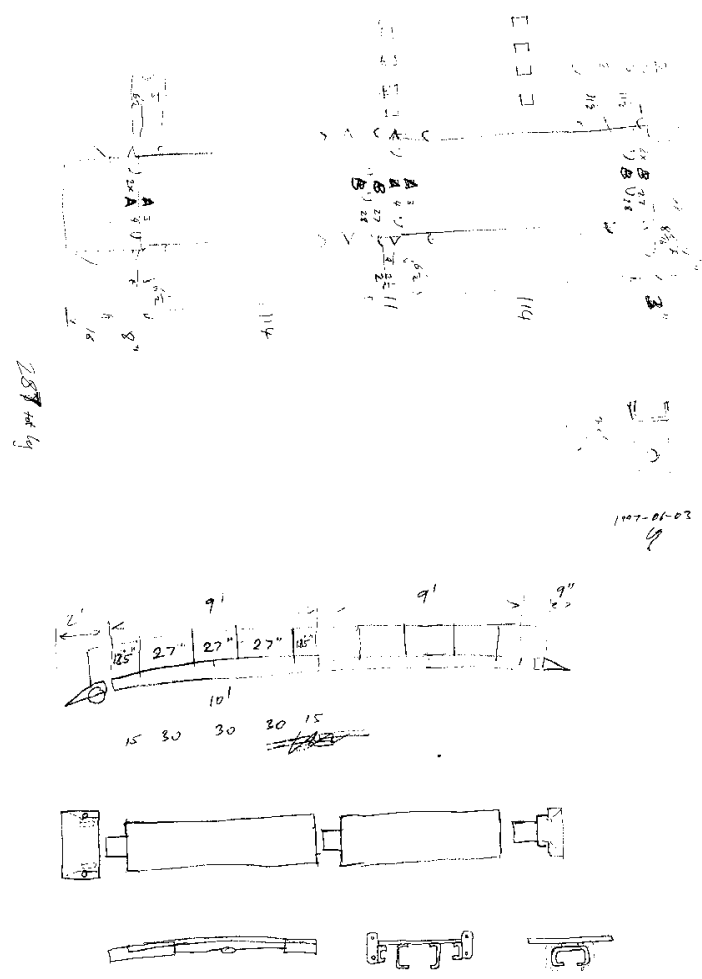

Figure 6 TS-Organ Structure for Gangway 
- embodying/laying out and detailing:

(P5a) establish what constructional parts and their arrangement are needed, in sketch-outline, in rough layout, with alternatives;

Some preliminary layout sketches were produced to explore the constructional possibilities, see figure 7 .
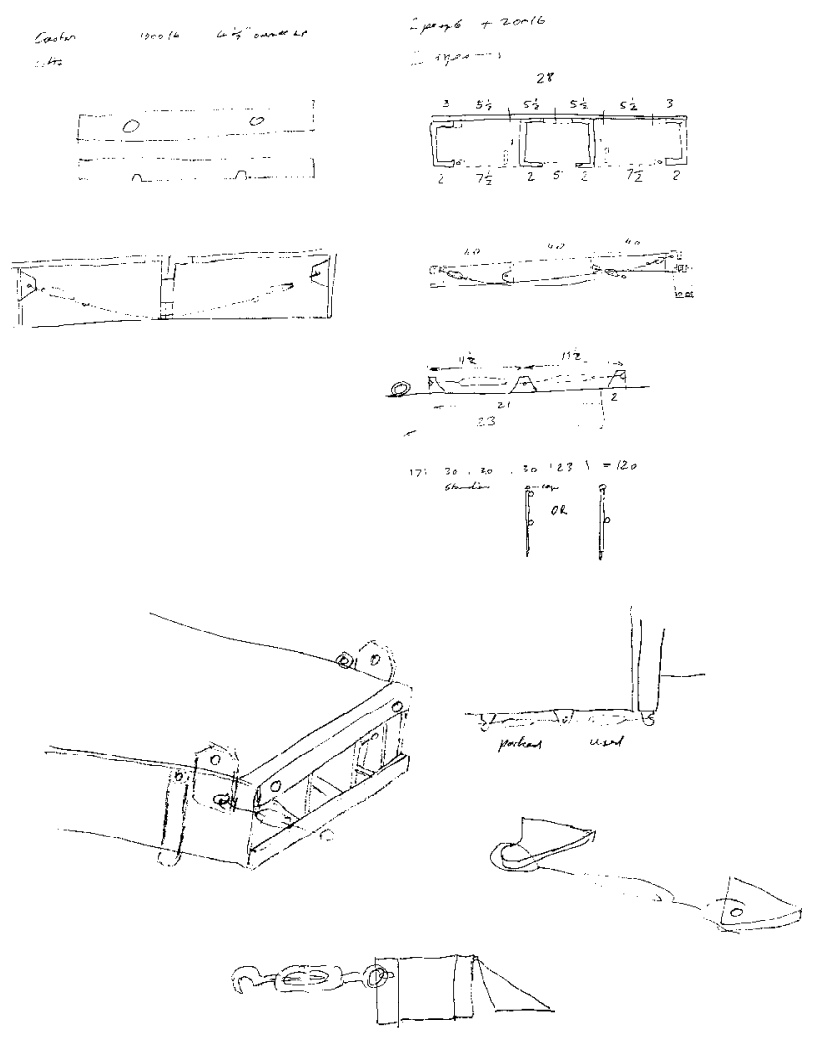

Figure 7 TS-Constructional Structure - Preliminary Layout

(P5b) establish what constructional parts are needed, in dimensional-definitive layout, with alternatives; (P6) establish what constructional parts are needed, in detail and assembly drawings, with alternatives.

For this project, the layouts and the detail drawings were produced by hand - pencil on paper. CAD could have been employed, but offered no real advantages.

A sample detail drawing and a sample assembly drawing is shown in figure 8 . The resulting gangway has been fully detailed for manufacture, eight sheets of $430 \times 280 \mathrm{~mm}(17 \times 11 ")$ plain white paper.
Fabrication took place in the summer of 1997. Tests and adjustments were specified to ensure that the gangway was serviceable. Nevertheless, the product, the gangway, can readily be seen as the result of innovative, and even creative activity.

For a fuller discussion of the recommended method, see [3],[4]. A more experienced engineering designer will no doubt be able to reach a similar result whilst neglecting one or more of the earlier of these formal steps and models.

\section{References}

[1] Hubka, V., and Eder, W.E. (1988) Theory of Technical Systems: A Total Concept Theory for Engineering Design, New York: Springer_Verlag

[2] Hubka, V. and Eder, W.E. (1996) Design Science: Introduction to the Needs, Scope and Organization of Engineering Design Knowledge, London: Springer-Verlag, http://deseng.ryerson.ca/DesignScience/

[3] Eder, W.E. and Hosnedl, S (2008) Design Engineering: A Manual for Enhanced Creativity, Boca Raton: CRC-Press

[4] Eder, W.E. and Hosnedl, S. (2010) Introduction to Design Engineering - Systematic Creativity and Management, Leiden (The Netherlands): CRC Press / Balkema

[5] Eder, W.E. (2009a) 'Why Systematic Design Engineering?' in Proc. $6^{\text {th }}$ Symposium on International Design and Design Education, August 30 - September 2, 2009, San Diego, California, USA, New York: ASME, paper number DETC2009-86067

[6] Eder, W.E. (2012c) 'Engineering Design vs. Artistic Design - A Discussion', paper number 7 in Proc. Canadian Engineering Education Association CEEA 2012 Conference, 17-20 June 2012, University of Manitoba, Winnipeg, MB

[7] Eder, W.E. (ed.) (1996) WDK 24 - EDC - Engineering Design and Creativity - Proceedings of the Workshop EDC, Pilsen, Czech Republic, November 1995, Zürich: Heurista

[8] Gay, P. (1997) Pleasure Wars - The Bourgeois Experience: Victoria to Freud, Vol. 5, Norton

[9] Caravan Stage Barge (2010) http://www.caravanstage.org

\section{CLOSURE}




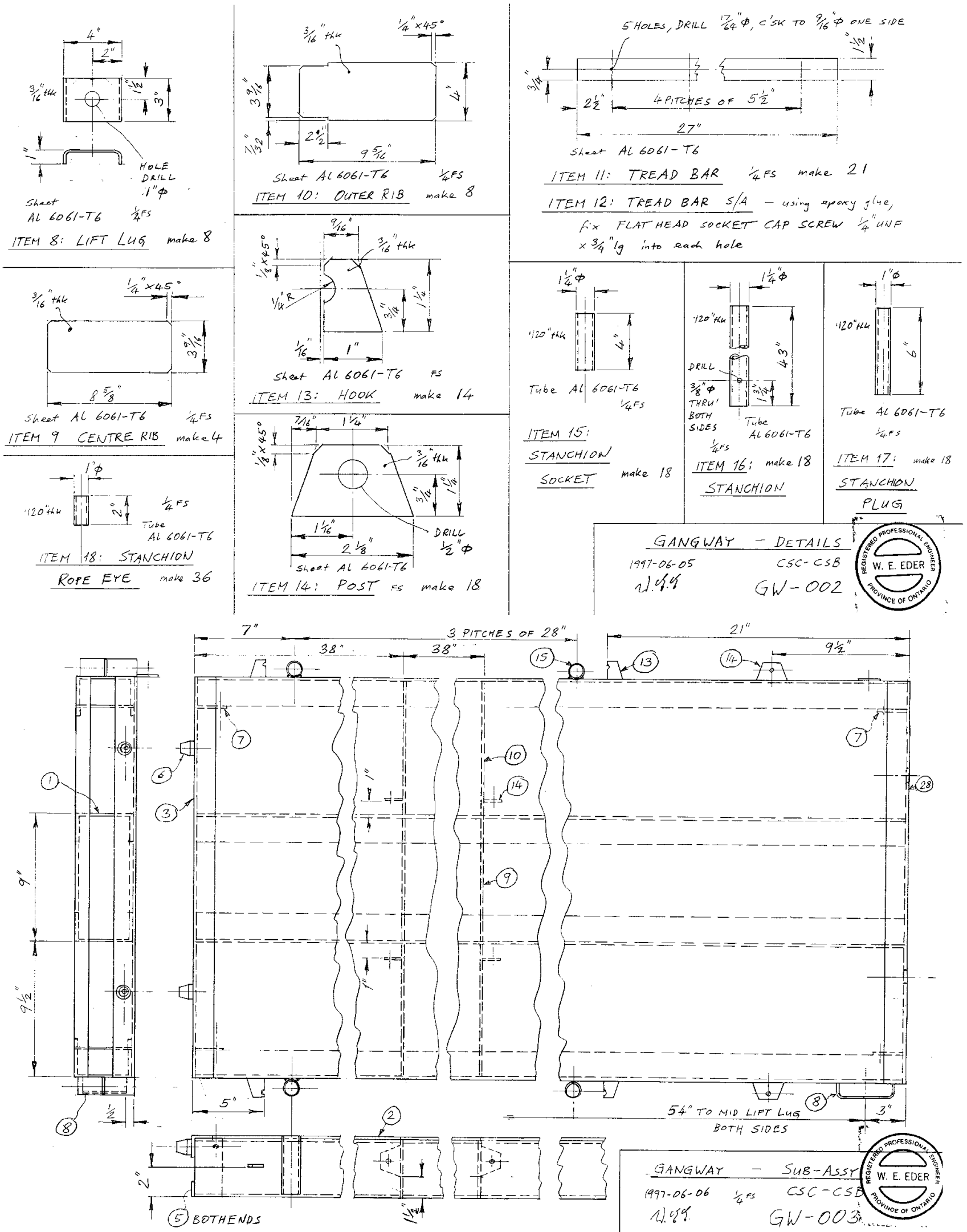

Fig. 8 Detail and Assembly drawings for Stage Barge Gangway 